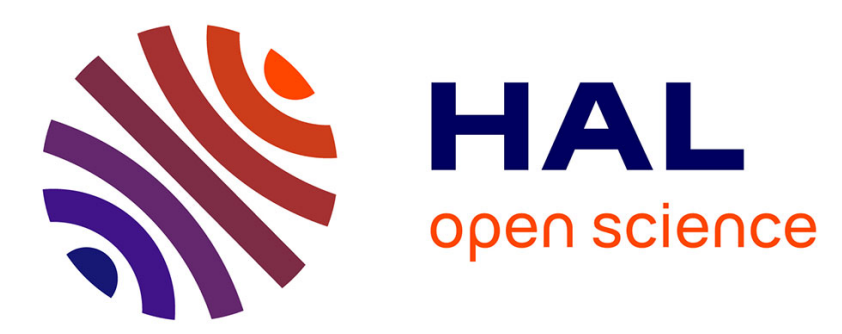

\title{
A Simple Analytical Model for Ballistic Impact in Composites
}

\author{
I. Chocron Benloulo, J. Rodriguez, V. Sánchez Gálvez
}

\section{To cite this version:}

I. Chocron Benloulo, J. Rodriguez, V. Sánchez Gálvez. A Simple Analytical Model for Ballistic Impact in Composites. Journal de Physique IV Proceedings, 1997, 07 (C3), pp.C3-821-C3-826. 10.1051/jp4:19973139 . jpa-00255426

\section{HAL Id: jpa-00255426 https://hal.science/jpa-00255426}

Submitted on 1 Jan 1997

HAL is a multi-disciplinary open access archive for the deposit and dissemination of scientific research documents, whether they are published or not. The documents may come from teaching and research institutions in France or abroad, or from public or private research centers.
L'archive ouverte pluridisciplinaire HAL, est destinée au dépôt et à la diffusion de documents scientifiques de niveau recherche, publiés ou non, émanant des établissements d'enseignement et de recherche français ou étrangers, des laboratoires publics ou privés. 


\title{
A Simple Analytical Model for Ballistic Impact in Composites
}

\author{
IS. Chocron Benloulo, J. Rodríguez and V. Sánchez Gálvez
}

Dpto. Ciencia de Materiales, ETSI Caminos Canales y Puertos, Universidad Politécnica de Madrid, 28040 Madrid, Spain

\begin{abstract}
The analytical models already developed by Smith and Roylance for impact in yarns and impact in textiles have been used, together with a new failure criterion based on the energy that crosses each yarn, to build a simple analytical model of impact in textiles. This model has been checked with Dyneema armours and predicts accurately the residual velocity of Fragment Simulating Projectiles. The model has been completed with a delamination equation taken from Beaumont in order to include the composite characteristics of delamination. The result is a very simple model which simulates accurately the impact of a FSP into a composite armour with very few seconds of calculation in a personal computer.

Résumé. Les modèles analytiques développés par Smith et Roylance concernant l'impact de projectiles sur des fils et des tissus ont servi de base pour créer un modèle analytique simple avec un critère de fracture nouveau. Ce modèle a été contrasté avec des résultats expérimentaux et complété avec un modèle de délamination déjà utilisé par Beaumont dans sa thèse doctorale. Le résultat final est un modèle analytique très simple capable de simuler l'impact sur un matériau composite en quelques secondes de calcul avec une bonne précision.
\end{abstract}

\section{INTRODUCTION}

The use of reinforced materials in engineering applications has shown a rapid growth in the last few years. A lot of metallic components have been moved and replaced by composite elements. To see the advantages in using composite materials, a comparison between their properties and those of more traditional materials should be done in terms of specific values (per unit of weight). The design of protections against impact loads is not an exception to this tendency. Fabrics and composite materials are the main component of bullet proof vests or the add-on plate of lightweight armours. The loading process in these applications implies very high rates of strain (around $10^{5}-10^{6} \mathrm{~s}^{-1}$ ).

Three different approaches can be followed to face the design of composite protections against ballistic impacts: empirical, numerical or analytical. The empirical method involves a wide experimental program to cover the range of projectiles, velocities and target thicknesses. The goal is a data base which can be used to predict the result of problems within the range analyzed, but without capability to extend the solutions when the armour configuration is substantially changed.

Numerical approach, based on finite elements or finite differences methods, needs to know how the composite behaves under triaxial stress states and extremely high strain rates. Even if the material characterization is good enough, these methods are so expensive in computing time that they are not suitable in most of design applications.

Analytical modeling of impact problems in composite materials is a compromise solution between accuracy, cost and physical knowledge. The analytical approach rests on very hard hypotheses which allow to simplify the solution. A typical problem can be solved in seconds, providing then a useful tool to designers, at least as a first step.

In this paper, a simple one dimensional analytical model for ballistic impact in composites is presented. The objective is to predict the residual velocities of projectiles from 0.2 to 10 grams, impacting a target at velocities from $300 \mathrm{~m} / \mathrm{s}$ to $1500 \mathrm{~m} / \mathrm{s}$. The model is based on the one applied to yarns and afterwards modeling is extended to a fabric and finally to a composite. An original failure criterion based on energetic considerations is proposed, although a damage interpretation can also be admitted. 


\section{ANALYTICAL MODEL}

The model subdivides a very complex phenomenon, like the high velocity impact in composites, into more simple and understandable problems. A composite is a textile fabric, woven or not, with some organic matrix. Thus it has been found interesting to face the problem in the way already presented by Beaumont [1] or Chocron [2] in their Ph. D. Thesis: the ballistic impact into a yarn studied by Smith [3] together with some hypotheses allows an analytical approach of the impact onto textile fabrics (see for example Roylance [4]). Assuming a brittle matrix is added to the fabric and that the tensile waves reflecting from the rear of the armour break the matrix during the impact it is possible to build a simple set of ordinary differential equations that can be solved with Adams-Moulton predictor-corrector method.

\subsection{Analytical model for impact on a yarn}

The transverse impact of a projectile onto a yarn has been mathematically solved by Smith [3] in 1958. His results were, see Figure 1, that a yarn transversally impacted shows two waves traveling along it. The longitudinal one travels at the speed of sound and initiates the movement of the particles in the yarn towards the projectile. The transversal wave is slower and make the particles move in the same direction of the projectile. Assuming the hypotheses of point impact, constant velocity of the projectile and a linear elastic yarn, Smith found the following equations:

$$
\begin{gathered}
\mathrm{U}=c(\sqrt{\varepsilon(1+\varepsilon)}-\varepsilon) \\
\mathrm{V}=c \sqrt{\varepsilon(2 \sqrt{\varepsilon(1+\varepsilon)}-\varepsilon)}
\end{gathered}
$$

where $\varepsilon$ is the yarn strain, $c$ the sound speed, $U$ the speed of the transverse wave and $V$ the velocity of the projectile.

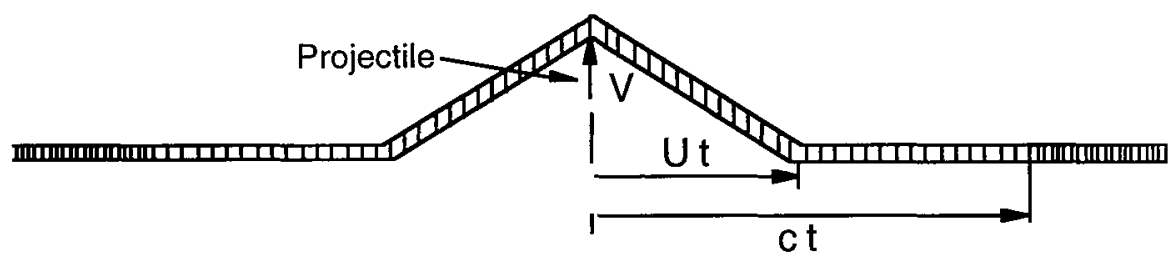

Figure 1: Transversal and longitudinal waves in a yarn impacted by a projectile

\subsection{Analytical model for impact onto a fabric}

Roylance [4] studied the transverse impact onto a textile fabric with its discretization. He assumed each crossover was a lumped mass subjected to the forces of the four crossovers that surround it. This model was further improved by Cunniff [5] giving good results but, due to the calculation method, spending many computing hours of a workstation. Navarro [6] faced the problem from the analytical point of view, trying to understand the phenomenological aspects and, modeling the impact process in a unidirectional fabric as a one dimensional problem. Chocron [7] improved this model, showing that Smith's equations (1) and (2) are still valid when the projectile velocity is not constant if we apply them to the impacted point in the fabric. He also proposed a new failure criterion for fabrics impacted at high velocity. In the following a brief summary of the more important results of this model is presented.

The equation of motion of the projectile can be written: 


$$
M_{p} \frac{d \bar{V}}{d t}=2 \bar{F}
$$

where $M_{p}$ is the mass of the projectile (assumed constant), $V$ its velocity and $F$ the force acting on the projectile, see Figure 2 for an outline of the problem.

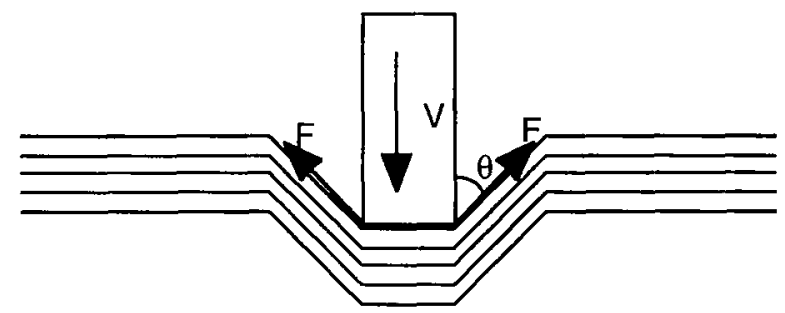

Figure 2: Sketch of the impact of a projectile onto a fabric

In order to simplify the problem some hypotheses will be assumed: the fabric behaviour is unidirectional even if it is woven, the strain is uniform for all layers under the projectile and only yarns in direct contact with the projectile contribute to its slowing down. Hence, the force can be explicitly written as:

$$
\mathrm{F}_{\mathrm{y}}=\mathrm{E} \varepsilon \mathrm{n} \mathrm{S} \mathrm{n}_{\mathrm{l}} \cos \theta
$$

where $F_{y}$ is the component of the force in the direction of motion, $E$ the Young modulus of the yarns, $\varepsilon$ the strain of the fabric under the projectile, $n$ the number of yams in direct contact with the projectile, $S$ the section of the yarn and $n_{l}$ the number of layers of the fabric. Smith's model gives the strain and the angle $\theta$ thus, it is possible to integrate Equation (3), the remaining problem being determining the time of failure.

The last step is the failure criterion. Prosser [8] suggested that the energy absorbed by the fabric when full perforation occurs should be constant independently of the impact velocity. This hypothesis together with the energy equation which states that the energy lost by the projectile during the impact has to be equal to the energy distributed in the fabric (drag is not considered):

$$
\frac{1}{2} M_{p}\left(V_{s}^{2}-V_{r}^{2}\right)=\frac{1}{2} n_{n_{1}} S E c \int_{0}^{t} \varepsilon^{2}(t) d t
$$

allows the adoption of a new failure criterion where the unknown is the time of failure of the fabric:

$$
\frac{M_{p} V_{50}^{2}}{n_{n_{1}} S E c}=\int_{0}^{t_{v s}} \varepsilon^{2}(t) d t=R
$$

where $R$ is a constant, called failure constant, only dependent on the configuration, but not on the impact velocity and $t_{\mathrm{V} s}$ is the time of failure. $\mathrm{V}_{50}$ is the ballistic limit.

The constant $R$ must be obtained experimentally for one reference configuration (called $R_{0}$ ) whilst for others configurations (called configurations $i$ ) its value can be analytically found in the following manner: 


$$
R_{i}=R_{0} \frac{\left(M_{p}\right)_{i}}{\left(M_{p}\right)_{0}} \frac{n_{0}}{n_{i}} \frac{\left(n_{1}\right)_{0}}{\left(n_{1}\right)_{0}} \frac{\left(V_{50}^{2}\right)_{i}}{\left(V_{50}^{2}\right)_{0}}
$$

\subsection{Analytical model for impact onto a composite material}

Beaumont [1] studied carefully the low velocity impact $(50-500 \mathrm{~m} / \mathrm{s})$ on carbon/epoxy composites. His model assumes that the delamination front coincides with the transversal wave which propagates in the composite. The percentage of volume delaminated is given by:

$$
\dot{A}=4\left(\frac{1}{L}\right)\left[\frac{c}{2 V\left(1-5\left(\frac{V}{4 c}\right)^{2 / 3}\right)}\right]^{1 / 3} \sqrt{A}
$$

here $\mathrm{A}$ is the percentage of volume delaminated, $\dot{\mathrm{A}}$ its time derivative and $\mathrm{L}$ a characteristic length of the plate impacted. Equation (3) can be modified in order to take into account the energy of delamination. This has also be done by Beaumont concluding that the velocity of the projectile can be computed with the differential equation:

$$
M_{p} V \frac{d V}{d t}+\pi L^{2} G A+2 F V \cos \theta=0
$$

in this equation $G$ is the energy necessary to delaminate $1 \mathrm{~m}^{2}$ of composite. The equations (1)-(2) and (6)-(9) constitute a set of 6 equations with 6 unknowns $(U(t), V(t)$, $\left.\varepsilon(t), \theta(t), A(t), t_{s s}\right)$ easily solvable by, for instance, the Adams-Moulton predictorcorrector method.

\subsection{Application to impact into Dyneema composite plates}

Dyneema is the trade mark for a polyethylene fiber fabric with very good properties impact properties. Both fabric and composite armours are available by DSM. The ballistic limit of Dyneema armours can be explicitly written (for Fragment Simulating Projectiles) with a very simple expression published by Van Gorp [9]:

$$
\mathrm{V}_{50}=232 \delta^{0.5} \mathrm{~W}^{-1 / 6}
$$

where $\delta$ is the areal density of the armour in $\mathrm{kg} / \mathrm{m}^{2}$ and $\mathrm{W}$ the mass in grams of the projectile. This equation allows the calculation of the failure constant for each configuration with the expression (7) and then the problem of the impact can be fully solved.

Figure 3 shows the comparison of analytical (solid lines) and experimental (circles) results for impact of different FSP projectiles into a Dyneema fabric armour $\left(14.41 \mathrm{~kg} / \mathrm{m}^{2}\right)$. The energy lost by the projectile includes the air drag during its flight between the velocity measurement photoelectric panels. Classified experimental results are only available for $7.62 \mathrm{~mm}$ FSP ( 0.3 in., 2.85 grams, 44 grain). In this case the armour is a fabric so the delamination energy per square meter has been set to zero. The experimental results are well predicted by the very simple analytical model developed above. 


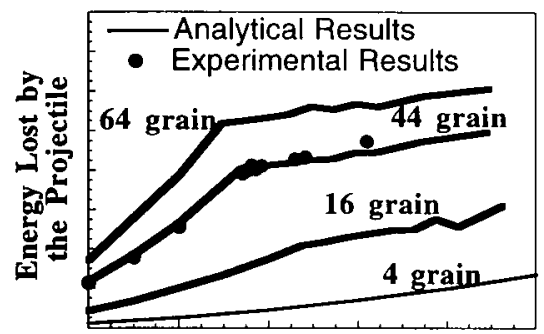

Impact Velocity

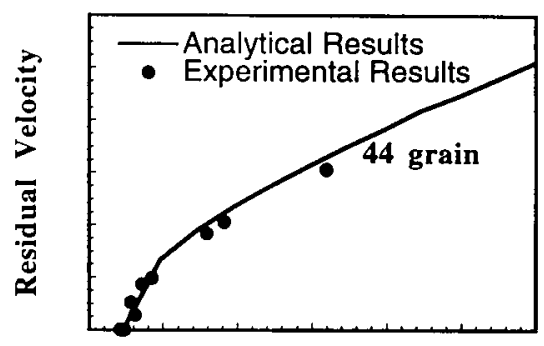

Impact Velocity

Figure 3: Comparison of analytical and experimental results for impact into Dyneema armour.

Figure 4 illustrates analytical results for the impact of a 1.1 gram FSP against different Dyneema composite panels, now with a delamination energy of $G=1500 \mathrm{~J} / \mathrm{m}^{2}$. For one of the panels $\left(5 \mathrm{~kg} / \mathrm{m}^{2}\right)$ simulations with $\mathrm{G}=0 \mathrm{~J} / \mathrm{m}^{2}$ and $\mathrm{G}=2500 \mathrm{~J} / \mathrm{m}^{2}$ in order to ascertain the influence of this parameter are also included. As it can be seen the importance of the matrix diminishes with the impact velocity. It is also posible to check that for this range of striking velocities the matrix almost does not affect the performance of the armour, being always pernicious.

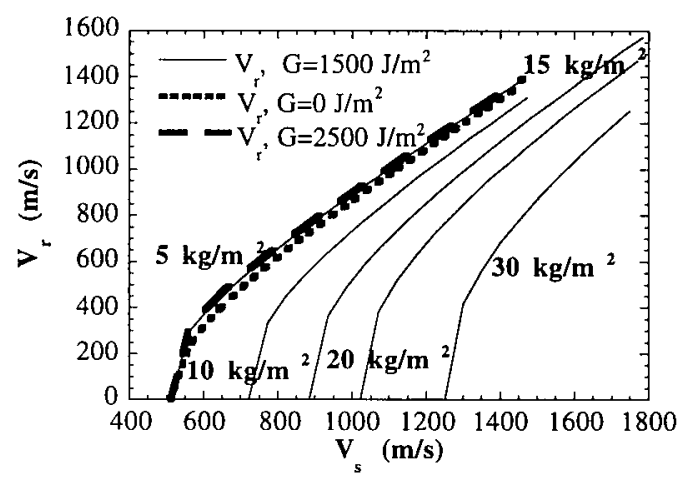

Figure 4: Residual versus impact velocity for impact onto various Dyneema armours

\subsection{Discussion}

One of the outstanding characteristics of the model described is the time dependent failure criterion. The simple criteria based on critical values of strain or stress do not represent the failure process properly. According to expression (2), the maximum strain at the impact point appears at the initial time, but from the experimental results it is clear that the failure process need some time. The decrease of strain can be explained through the material flow from other parts of the target. Although the criterion has been introduced in terms of energy, the ideas above commented suggest the interpretation of a damage accumulation process.

Given the hypotheses already introduced, a time dependent damage variable $D(t)$ can be defined and the following equation of damage evolution is postulated:

$$
D(t)=\omega
$$

where $\omega$ is the elastic strain energy stored per unit of volume, or explicitly:

$$
\omega=0.5 \mathrm{E} \varepsilon^{2}
$$


Therefore $\mathrm{D}(\mathrm{t})$ can be written as:

$$
\mathrm{D}(\mathrm{t})=\int_{0}^{\mathrm{t}} 0.5 \mathrm{E} \varepsilon^{2} \mathrm{dt}
$$

$E$ is the Young modulus of the yarns. The failure criterion is based on the value of the variable $D(t)$. When a critical value $D_{c}$ is reached, the fabric fails and the projectile goes through it with its residual velocity (no drag between the fabric and the projectile is considered). Thus the failure criterion can be established as:

$$
\mathrm{D}(\mathrm{t})=\mathrm{D}_{\mathrm{C}}
$$

$\mathrm{D}_{\mathrm{C}}$ is a characteristic of the material that can be calculated in terms of the damage at the ballistic limit of the fabric. This damage explanation is an alternative to the energetic one, which states that the composite fails when an amount of energy has traversed through the individual yarns.

\section{CONCLUSIONS}

In this paper a simple phenomenological model for high velocity impact on composites has been developed obtaining good results when comparing with experimental or numerical tests. Ideas taken from Smith, Roylance and Beaumont have been gathered together with a new failure criterion leading to a model that can deal with impact onto textile or composites and also with ceramic/composites armours.

\section{Acknowledgments}

Authors would like to thank Philip Cunniff (U.S. Army Natick, MA, USA) and Carlos Navarro (Universidad Carlos III, Madrid, Spain) for very useful discussions. Also thanks to DSM for providing experimental results and to CICYT for its financial support.

\section{References}

[1] N. Beaumont, Contribution à l'Étude de l'Impact d'une Bille sur une Plaque en Matériau Composite, Thèse Doctorale, 1991

[2] I. S. Chocron, Caracterización Mecánica y Desarrollo de Modelos de Materiales Compuestos Sometidos a Cargas de Impacto, Tesis Doctoral, 1996

[3] Jack C. Smith, Frank L. McCrackin, Herbert F. Schiefer, Stress-Strain Rlationships in Yarns Subjected to Rapid Impact Loading. Part V: Wave Propagation in Long Textile Yarns Impacted Transversely, Textile Res. J., April, 288-302, 1958

[4] David Roylance, Anthony Wilde \& Gregory Tocci, Ballistic Impact of Textile Structures, Textile Research Journal, January, 34-41, 1973

[5] Philip M. Cunniff, An analysis of the system effects in Woven fabrics under ballistic impact, Textile Research Journal, 62, 9, 495-509, 1992

[6] C. Navarro, J. Rodríguez, R. Cortés, Analytical Modelling of Composite Panels Subjected to Impact Loading, Journal de Physique IV, Colloque C8, supplément au Journal de Physique III, 4, Sept, 515-520, 1994

[7] Isaias Sidney Chocron Benloulo, J. Rodríguez, V. Sánchez Gálvez, A Simple Analytical Model to Simulate Textile Fabric Ballistic Impact Behavior, Textile Research Journal, accepted in its revised form, 10-96

[8]Robert A. Prosser, Penetration of Nylon ballistic panels by fragment-simulating projectiles.Part I: A linear aproximation to the relationship between the square of the V50 or Vc striking velocity \& the number of layers of cloth in the ballistic panel.Part II: Mechanism of Penetration, Textile Research Journal, February,61-85, 1988

[9]E.H.M. van Gorp, L.L.H. van der Loo \& J.L.J. van Dingenen, A model for HPPEBased lightweight add-on armour, Ballistics 93, 1993 